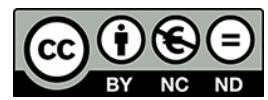

\title{
Taking handicap into account: Systemic features
}

\author{
Patrick FARFAL \\ PatSys \\ Paris, France \\ pfarfal.patsys@sfr.fr
}

\begin{abstract}
Because of many features of handicap, such as the number of actors and interactions, the complexity of the field, handicap must be considered from a system point of view, and dealt with as any system. That makes it possible to build a comprehensive response to the question of the inclusion and full citizenship of people with disabilities, better than some fragmentary solutions often proposed. The paper emphasizes relationships inside the disability field and external relationships with the environment, namely valid people in everyday life and work field; the consideration of those external relationships leads to the compensation of handicap for a better accessibility to buildings, transports, care, communication, and so on; unexpected spin-offs of that compensation on the whole of population can be observed.
\end{abstract}

\section{INTRODUCTION}

The approach of handicap must resolutely be systemic, due to the high number of people with disabilities, the complexity of the question, and the statement that the answers, officially provided to help disabled people to benefit from all their rights to citizenship, are too often fragmentary.

This paper develops an integrated approach and comprehensive view, based on coordinated actions, of disability treatment.

To conveniently deal with the matter, two questions must be answered: Why deal with systemic approach as far as disability is concerned? What about "Interaction with Ecosystems"?

NEED FOR SYSTEMIC APPROACH

\section{Problem complexity}

1 First of all, disability (or handicap) obviously and immediately addresses the questions of social link and citizenship, which means many interactions between disabled and valid people; and those interactions are reciprocal by definition.

2 Second, a few figures (see for example [1]) give an idea of the extent of that matter:

- nearly 5 million of disabled people (strictly speaking) can be counted in France (10 million in a broad sense), among them 1.8 million with serous disability

- 1 European out of 10 is concerned

- $15 \%$ of world population (more than 1 billion) was disabled in 2010 , versus $10 \%$ in the 70 's; the number of disabled people is increasing, due to the ageing of population (resulting in higher risk for elderly people) and the increasing of chronic health disorders associated with a handicap: diabetes, cardiovascular or mental diseases 
- only $15 \%$ of disabilities are contracted at birth: any valid person may contract a handicap any day (accident, incapacitating health disorder...)!

- unemployment rate in the disabled population is twice as high as the one of valid people in France (400 000

disabled people unemployed in 2013)

- 6 billion $€$ were granted by the European Commission only to fight against social exclusion of young people in 2013.

Conclusion: handicap as a fact is far from being marginal!

3 Diversity is well identified as a complexity factor; in the field of disability, diversity, differences, multiple singularities are recurrent terms

- $\quad$ sensory and motor disabilities

- $\quad$ psychic and mental disabilities

- diversity of pathologies.

Maybe the best illustration of diversity is the definition of handicap given by the French law $\mathrm{n}^{\circ}$ 2005-102 February11" 1 , 2005, "pour l'égalité des droits et des chances, la participation et la citoyenneté des personnes handicapées (for the equality of rights and chances, participation and citizenship of people with disabilities)" [2]:

“...any activity limitation or restriction of participation in social life suffered in her environment by a person due to lasting or final substantial deterioration of one or several physical, sensory, mental, cognitive or psychic functions, to multi-disability or incapacitating health disorder "

That definition can be also found in [3]. Note that the French 2005 law is the first one in France to explicitly define handicap.

Considering that law, it can be seen that disability addresses the question of fight against discrimination, in accordance with the motto "different yet equal" [4].

4 Diversity also addresses the high numbers of actors in the field of handicap: not only disabled people themselves, but also other ("valid") persons, and bodies in charge of disability:

- private \& public sectors, associations

- care \& cure centers, financial bodies,

with the result that, facing that inflation of bodies, people speak of "institutional jungle", in French "maquis institutionnel" (to be compared to a limited number of laws in France: 1950's, 1975, 1987, 2002, 2005).

\section{System interactions}

1 Interactions inside the "Disability system", between disabled people and their internal environment, namely the set of laws and bodies (care and cure, financial), aim at "changing the attention to disability ", which means, once again, a reciprocal relationship; disability, indeed, is an interaction between personal and environmental factors.

2 Interactions of the "Disability system" with its "Ecosystem" are the very core of the question: as written in the 2005 law: "...any activity limitation or restriction of participation to social life ", the "Disability system" has tight reciprocal relationships with the social field: valid people, buildings, 
transportation..., education field: primary and secondary teachers, professors and lecturers, buildings..., and work field: valid workers, especially recruiting ones and managers, offices...

Some kind of "blocking loop", or vicious circle, may be met considering the interactions of the "Ecosystem" with people with disabilities:

- social exclusion, shame

- deprivation of opportunities in social, economic, human development

- lack of social, economic, cultural rights

- reduced participation in decision-makings, deprivation of civic and political rights

- social exclusion, shame

- etc.

3 Disability needs compensation: compensation means sensory or motor aid, desk fitting out, access to buildings, offices, shops, transports, communication...

The Environment itself, physical, social, and attitudinal, adapts to the disabled person! This is something really new and not so often met when considering systems, either natural or man-made.

\section{A few facts}

In practice, and generally speaking, individualism takes the lead over "living together".

Stereotypes and prejudices on disabled people became widespread among other people both in everyday life and at work: contrary to a widespread opinion, only $5 \%$ of disabled persons use a wheelchair! And only $1 \%$ of disabled workers! In the work field, people with disabilities are often deemed "less performative", "generating extra costs", "source of risks"... Such prejudices are just boundaries harmful to a convenient inclusion!

Inflation of bodies in charge of disability makes the system not easily readable; it can be discussed about the counter-performative feature of that situation; in systemic words, we are facing a nearly blocking loop.

Answer provided by some elected or administration people is most of the time fragmentary (e.g.: "You have only to develop training"; or just consider the inclusion, in the USA a few decades ago, of disabled children into " ordinary » schools without any other steps or prerequisites). Of course, training is one of the leverages, but under the condition to be integrated into a comprehensive arrangement of other actions.

\section{Approach of the question of disability}

As said in [1], "Disability is complex, dynamic, multidimensional, and contested.

Complexity of actors and complexity of interactions, insufficiency of some responses to exclusion and limited citizenship, deserve and demand a systemic approach.

Only that approach makes it possible to build a comprehensive response to the question of the inclusion and full citizenship of people with disabilities, better than some fragmentary solutions often proposed. The rest of the paper emphasizes relationships inside the disability field and external relationships with the environment, namely valid people in everyday life and work field.

HOW TO DEAL WITH A SYSTEMIC APPROACH TO DISABILITY?

\section{System aspects: the three basic elements}

Every time a matter is tackled from a system point of view, three elements must be identified: 
- Aim: "disability system" aims at ensuring the right of persons with disabilities to live and work, on an equal basis with others, i.e. inclusion and full citizenship of people with disabilities

- Structure: actors in the disability field have been mentioned here above: disabled people, lawmaker, bodies; an organisation exists, with multiple juxtapositions and fittings/encasings [5] (also named vertical and horizontal integration in man-made systems)

- Interactions: as shown in $\S$ II $B$, interactions do exist, inside the "Disability system" and with the environment, both possibly limited by the existence of boundaries

Actors and arrangements mentioned here above actually constitute a system.

\section{Systems Engineering view}

Systems Engineering is abundantly described in the technical literature, e.g. [6].

A classical view in Systems Engineering, used to distinguish "functions" to be operated by a system from the "components" and resources the system is made of, is the pyramidal one [7]:

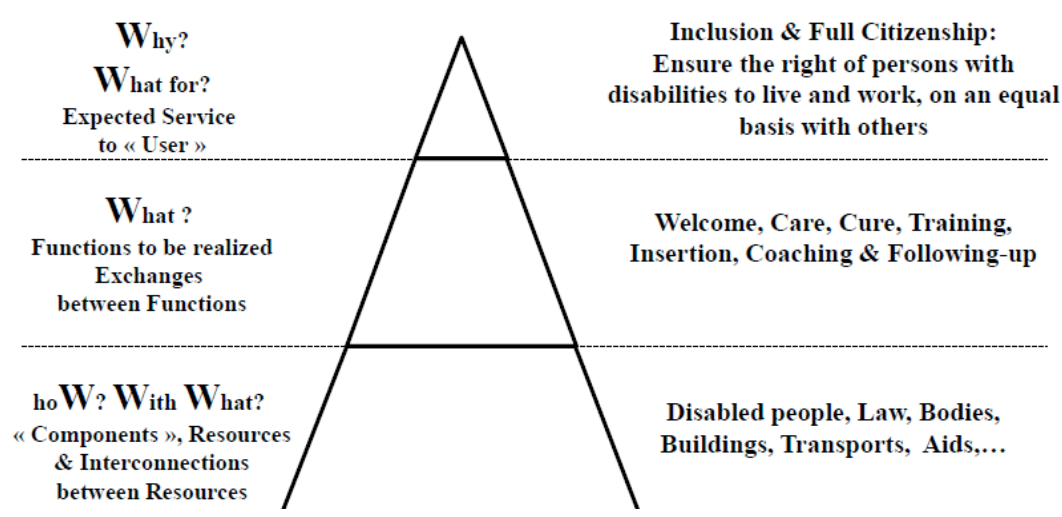

Fig. 1: Systems Engineering view

As shown hereafter, there is no unique correspondence between any function and component.

Systemic Triangulation [8]

To emphasize the role of time factor, it is interesting to use the Systemic Triangulation, which can be brought together with the Systems Engineering view.

This view introduces the time dimension; in spite of the way remaining to be covered to reach full citizenship for disabled people, the reference to the past enlightens the distance covered since the GreekRoman antiquity (the birth of a disabled child was considered as a punishment from gods...)

Considering that dimension also helps use the time factor in disability treatment, as explained in IV- $A$. 


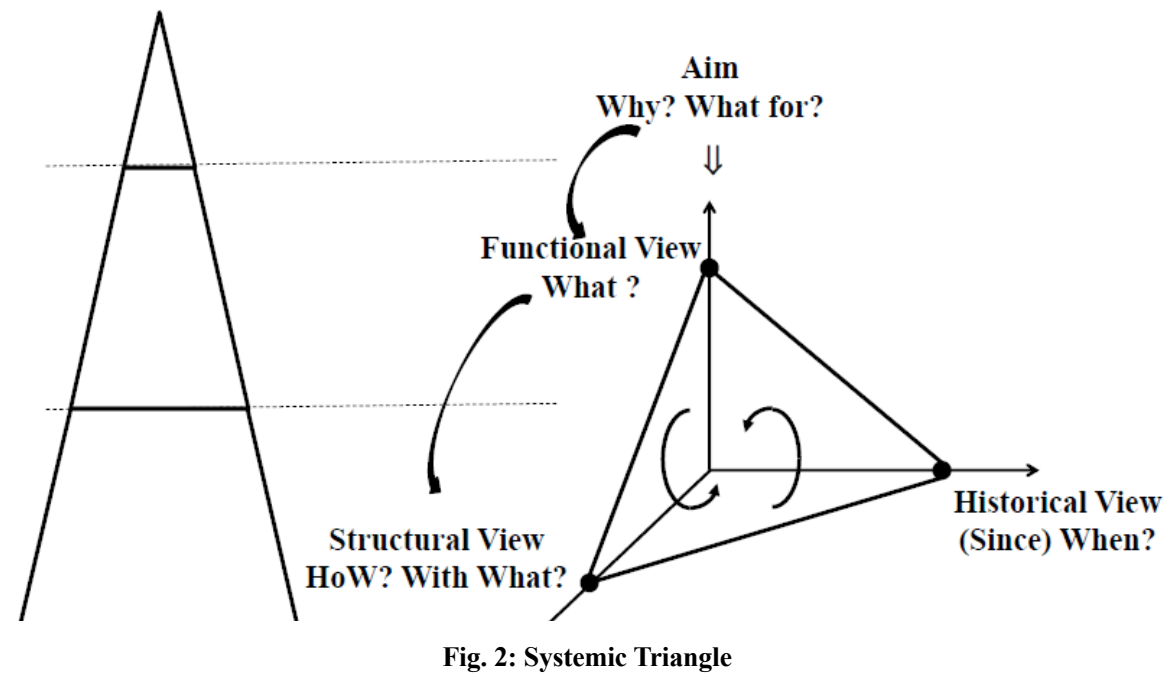

\section{Individual and medical model vs social model}

It is interesting to compare two models, a classical one, individual and "medical", and a new model well in line with the spirit of the French 2005 law, the social model:

- individual and "medical" model: the person has no use of her limbs/ moves in a wheelchair/ is deaf and/or blind/ in crisis/ not able to work/to move around/ uncommunicative and aggressive/ needs constant aid:

[x] according to that model, the disabled person is the problem

- social model: buildings are unsuitable/ transports are inaccessible/ city spaces are out of reach/ discrimination exists in education/ people with disabilities find few employment possibilities/ their incomes are modest/ their families are isolated/ people with disabilities meet segregative attitudes/large number of prejudices exist:

[x] according to that model, society (the Environment) is the problem!

As in Systems Engineering, or any systemic study, the selection of the model is a determining factor, insofar as it better fits reality.

One can appreciate the path covered since Antiquity, when disability was deemed a punishment from gods, until the slow and recent emergence of the social model of disability.

\section{THE 3 COMPONENTS OF A COMPREHENSIVE (HOLISTIC) VIEW}

\section{Consider the time factor}

Taking into account the historical view, and especially the importance of the time factor, makes it possible to emphasize the need for treating disability matter from childhood, from the very beginning of primary education: as it can be seen in primary schools that mix disabled and valid very young people, children, contrary to grown-ups, do not have stereotypes nor prejudices towards disability; consequently, acting from childhood greatly helps "change attention" and educate the point of view on disabled people. Note that education of disabled children is lacking efficiency: 20000 disabled children are not provided with schooling in France; only $20 \%$ of students passing the French baccalauréat (i.e. who are successful in secondary school) access to higher education; only $0.5 \%$ of students in higher education are disabled ones. 
Keeping in mind the time factor, all the actions to be implemented must be thought about as long-lasting ones; what has been said about childhood must be continued with continuous actions [4]:

- prepare young people future with young people themselves: maintain the priority of schooling in the ordinary field, favour accessibility to higher education by support plans with work field and student associations

- $\quad$ secure everyone's route, as explained in $\S B$.

\section{Systemic treatment of disability implies coordinated actions}

"Coordinated actions" means "taking into account all the interactions between the actors", all at once lawmakers, bodies in charge of disability, school and university, work field, social environment, people with disabilities themselves.

The number of action fields is rather large [9]:

- Children: welcome, education, care

- Companies and employment: competences acknowledgement, recruitment...

- Administration: welcome and support, recognition of disabled worker status...

- Education: of disabled people, nursing staff, but also recruiting people and managers...

- Training: without training, the access to employment remains difficult

- Accessibility: to housing, buildings, transports, care, communication...

- Right to compensation: of sensory or motor disability...

- Cultural and associative life

- Cure and care.

An integrated approach, based on prevention, cure, and, generally speaking, taking care of disabled people, results in decompartmentalizing professionals and institutions, coordinated work in building everyone's route, and additional work in the offer of support. Once again, the main lines mentioned here above summarize that integrated approach [4]: prepare young people future with young people themselves, secure everyone's route, which means anticipate the risks of de-integration (exclusion).

\section{Even cure and care are of systemic nature}

The person must be treated in her whole, taking into account her social, professional and family environment [4]:

- therapeutic education makes the disabled person participate in her treatment

- medicine acts at each step of the care path

- care is directed towards the transition to social and occupational rehabilitation; for example, after a disease or accident, as soon as a functional rehabilitation starts, actions are taken for the social, professional and family reintegration (early integration initiative)

- the disabled person is acting throughout her cure and care path. 


\section{CONCLUSION}

\section{Role of associations}

Many associations are dedicated to disability: they welcome, treat, cure and care, educate, train, integrate, support people with disabilities

Others include a disability part in cultural, artistic or sports activities, welcoming people with disabilities.

All of them play a major role in that integrated approach.

\section{Spin-offs of compensation}

Unexpected spin-offs of the compensation of handicap can be seen: the adaptability of some space (building, transport) to the needs and constraints of a person with a loss of autonomy is not a simple respect of law as regards accessibility, but is broadened to the quality of use of "life spaces" for everybody, taking into account the needs and constraints of the whole of people [10]; a few examples:

- when ramp (for wheelchairs) and stairs both exist inside a building, everybody takes the ramp!

- as soon as a bus is equipped with an access platform for wheelchairs, everybody uses it with pushchairs!

- remote control for TV was invented for a disabled person!

So, by some kind of circular causality between disabled people and others - virtuous circle -, the disabled person often appears to enlighten the needs of the whole.

Considering Systems Engineering vocabulary, that amounts to speaking of taking into account the needs and constraints of all the stakeholders, which is an essential condition of secure outcome of a project.

The adaptation of the environment to the disabled person, in the very scope of the February $11^{\text {th }} 2005$ French law, as well as the claim of her full citizenship (schooling, employment, social life...), with its consequences onto the whole of people, is not the least surprise arisen from thinking about disability.

\section{REFERENCES}

[1] World Health Organisation and The World Bank, World report on disability, 2011 (summaries exist in other languages)

[2] Loi n 2005-102 du 11 février 2005 pour l'égalité des droits et des chances, la participation et la citoyenneté des personnes handicapées

[3] World Health Organisation, International Classification of Functioning, Disability and Health (ICF), 2001

[4] Projet Associatif 2011-2015 : "Vivre ensemble égaux et différents", L'ADAPT (Assocation pour l'insertion sociale et professionnelle des personnes handicapées)

[5] Pierre Bricage, The Metamorphoses of the Living Systems: The Associations for the Reciprocal and Mutual Sharing of Advantages and of Disadvantages - 6e congress européen de science des systèmes, 19-22 septembre 2005

[6] INCOSE (International Council On Systems Engineering) 2012 - Systems Engineering Handbook - A guide for system life cycle processes and activities, version 3.2.2 - INCOSE-TP-2003-002-03.2.2

[7] James Martin, Information Engineering: A trilogy. Introduction - Prentice Hall, 1989

[8] Daniel Durand, Emmanuel Nunez, An operative pedagogy of the system science approach, Res Systemica, 2002

[9] Elections présidentielle et législatives 2012, municipales 2014 - Le Pacte citoyen Emploi et Handicap de L'ADAPT (association pour l'insertion sociale et professionnelle des personnes handicapées)

[10] Présentation synthétique de la démarche HQU (Haute Qualité d'Usage) et de la mission A.M.U. (Assistance à Maitrise d'usage), CRIDEV (Centre de Recherches pour l'Intégration des Différences dans les Espaces de Vie) - 2008 
